\title{
Corrigendum: Strong, tough and stiff bioinspired ceramics from brittle constituents
}

Florian Bouville, Eric Maire, Sylvain Meille, Bertrand Van de Moortèle, Adam J. Stevenson and Sylvain Deville

Nature Materials 13, 508-514 (2014); published online 23 March 2014; corrected after print 10 November 2017

In the original version of this Article, the R-curves, which quantify how the toughness increases when the crack propagates, were measured following published guidelines (M. E. Launey, Acta Mater. 57, 2919-2932; 2009). Robert Ritchie (Lawrence Berkeley National Laboratory) proposes that the 2013 ASTM E1820 standard (Standard Test Method for the Measurement of Fracture Toughness) is a more appropriate guideline. The authors agree, and have therefore corrected the toughness values in the Article to meet the ASTM standard. Specifically, Figs 3c,j and 4 have been amended (shown below), and the original toughness values (in MPa $\mathrm{m}^{1 / 2}$ ) of 22 (abstract and page 510) and 21 (page 511) have been replaced with 17.3 and 16.4, respectively.

For consistency, the following changes have been made. On page 510, the text "By taking into account the local deflection as well as the other dissipation mechanisms with a J-integral, and by using the equivalence in the stress intensity factor, we find that the maximum increase of toughness is extremely high, around $22 \mathrm{MPa} \mathrm{m}^{1 / 2}$. This corresponds to a $350 \%$ increase compared to the $K_{\mathrm{Ic}}$ toughness (600\% increase with respect to the reference alumina)." has been changed to "According to the ASTM criterion, the maximum increase of toughness is extremely high, around $17.3 \mathrm{MPa} \mathrm{m}{ }^{1 / 2}$. This corresponds to a $300 \%$ increase compared to the $K_{\mathrm{Ic}}$ toughness (500\% increase with respect to the reference alumina)."

On page 512, the sentence "The unique combination of specific strength $\left(\sigma_{\mathrm{f}} / \rho\right)$ and specific toughness $\left(K_{c} / \rho\right)$ of our bioinspired ceramic material actually matches that of engineering aluminium and magnesium alloys (Fig. $4 \mathrm{~b}$ ) while exhibiting higher hardness $(16 \mathrm{GPa})$, stiffness and operating temperature." has been changed to "The unique combination of specific strength $\left(\sigma_{\mathrm{f}} / \rho\right)$ and specific toughness $\left(K_{c} / \rho\right)$ of our bioinspired ceramic material actually matches that of glass-fibre-reinforced plastics (GFRP; Fig. $4 \mathrm{~b}$ ) while exhibiting high hardness (16 GPa), stiffness and operating temperature."

On page 513, the following sentence has been removed: "However, toughness measurements can be considered valid until the data becomes geometry dependent due to large-scale bridging ${ }^{37}$, which here corresponds to $\Delta a=0.8 \mathrm{~mm}$. The values reported here were thus always obtained within a valid range of crack extension."

In the caption of Fig. 4, "The nacre-like aluminas have specific strength/toughness properties similar to those of titanium or magnesium metallic alloys" has been changed to "The nacre-like aluminas have specific strength/toughness properties similar to those of GFRP".
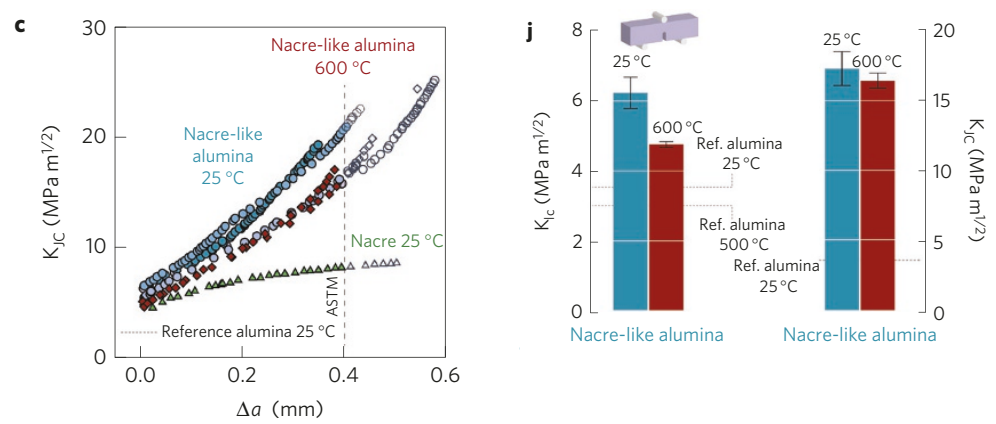

Figure 3
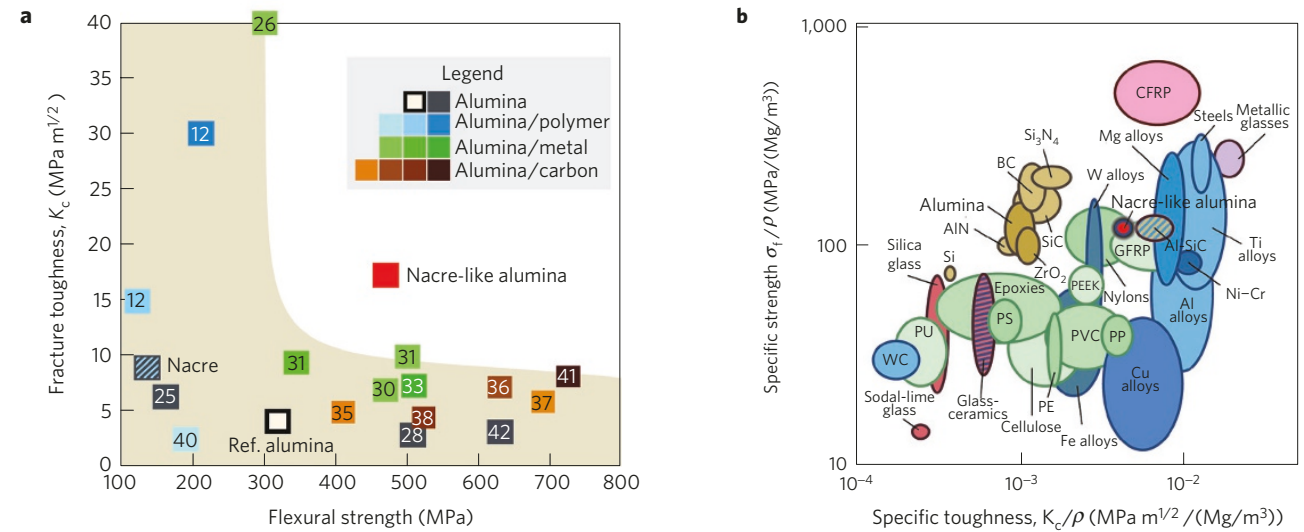

Figure 4 